\title{
Glutaminyl cyclase-mediated toxicity of pyroglutamate-beta amyloid induces striatal neurodegeneration
}

Andreas Becker ${ }^{1,2}$, Stephanie Kohlmann², Anca Alexandru², Wolfgang Jagla ${ }^{2}$, Fabio Canneva ${ }^{1}$, Christoph Bäuscher ${ }^{2}$, Holger Cynis ${ }^{3}$, Reinhard Sedlmeier ${ }^{2}$, Sigrid Graubner ${ }^{2}$, Stephan Schilling ${ }^{3}$, Hans-Ulrich Demuth ${ }^{2,3^{*}}$

and Stephan von Hörsten ${ }^{*}$

\begin{abstract}
Background: Posttranslational modifications of beta amyloid $(A \beta)$ have been shown to affect its biophysical and neurophysiological properties. One of these modifications is $\mathrm{N}$-terminal pyroglutamate ( $\mathrm{pE}$ ) formation. Enzymatic glutaminyl cyclase $(\mathrm{QC})$ activity catalyzes cyclization of truncated $A \beta(3-x)$, generating $\mathrm{pE} 3-\mathrm{A} \beta$. Compared to unmodified $A \beta, p E 3-A \beta$ is more hydrophobic and neurotoxic. In addition, it accelerates aggregation of other $A \beta$ species. To directly investigate $p E 3-A \beta$ formation and toxicity in vivo, transgenic (tg) ETNA (E at the truncated Nterminus of $A \beta$ ) mice expressing truncated human $A \beta(3-42)$ were generated and comprehensively characterized. To further investigate the role of QC in $\mathrm{pE3}-\mathrm{A} \beta$ formation in vivo, ETNA mice were intercrossed with tg mice overexpressing human $\mathrm{QC}(\mathrm{hQC})$ to generate double tg ETNA-hQC mice.

Results: Expression of truncated $A \beta(3-42)$ was detected mainly in the lateral striatum of ETNA mice, leading to progressive accumulation of $\mathrm{DE} 3-\mathrm{A} \beta$. This ultimately resulted in astrocytosis, loss of DARPP-32 immunoreactivity, and neuronal loss at the sites of pE3-A $\beta$ formation. Neuropathology in ETNA mice was associated with behavioral alterations. In particular, hyperactivity and impaired acoustic sensorimotor gating were detected. Double tg ETNAhQC mice showed similar A $\beta$ levels and expression sites, while $p E 3-A \beta$ were significantly increased, entailing increased astrocytosis and neuronal loss.

Conclusions: ETNA and ETNA-hQC mice represent novel mouse models for QC-mediated toxicity of truncated and $\mathrm{pE}$-modified A . Due to their significant striatal neurodegeneration these mice can also be used for analysis of striatal regulation of basal locomotor activity and sensorimotor gating, and possibly for DARPP-32-dependent neurophysiology and neuropathology. The spatio-temporal correlation of $\mathrm{pE} 3-\mathrm{A} \beta$ and neuropathology strongly argues for an important role of this $A \beta$ species in neurodegenerative processes in these models.
\end{abstract}

Keywords: ETNA, Pyroglutamate A $\beta$, Glutaminyl cyclase, Alzheimer's disease, TBA, Neurodegeneration, Neuroinflammation, Striatum

\footnotetext{
* Correspondence: hans-ulrich.demuth@probiodrug.de;

stephan.v.hoersten@ze.uni-erlangen.de

${ }^{2}$ Ingenium Pharmaceuticals GmbH, 82152 Martinsried, Germany

'Department of Experimental Therapy, Friedrich-Alexander-University

Erlangen-Nürnberg, Palmsanlage 5, 91054 Erlangen, Germany

Full list of author information is available at the end of the article
} 


\section{Background}

The formation of pyroglutamate (pGlu, pE) at the Nterminus of various peptides and proteins is catalyzed by glutaminyl cyclase (QC, QPCT) and its isoenzyme (isoQC, QPCTL). Alternatively, glutamine (Q) tends to form pGlu spontaneously under mild conditions at significant rates, which contrasts with glutamate (E) [1-3]. Likewise, glutaminyl peptides are preferred substrates for both QC and isoQC.

Pyroglutamate decreases solubility of beta amyloid $(A \beta)$, prevents further enzymatic degradation, and increases stability $[4,5]$ which may intensify the toxicity of several key proteins in a number of neurodegenerative diseases.

At present there are several hypotheses for posttranslationally modified proteins accounting for neuropathology in Parkinson's disease and Huntington's disease (HD) [6] as well as experimental evidence in familial British and Danish dementia [7-10] and Alzheimer's disease (AD) [11].

In case of $\mathrm{AD}, \mathrm{A} \beta$ is generated in the amyloidogenic pathway, a multi-step cleavage process of the amyloid precursor protein (APP) $[12,13]$ and pyroglutamate $A \beta$ $(\mathrm{pE} 3-\mathrm{A} \beta)$ is formed enzymatically during posttranslational peptide maturation via cyclization of $\mathrm{N}$-terminal glutamate residues of truncated $A \beta(3-x)$ species by $Q C$ like enzymatic activity $[2,14]$. The characteristic properties of pE3-A $\beta$, high aggregation propensity and stability, as well as a strong tendency to seed further aggregation of other $A \beta$ species $[9,15,16]$, result in an $A \beta$ form with increased toxicity.

Recently, QC-dependent formation of small amounts of $\mathrm{pE} 3-\mathrm{A} \beta$ inducing decreased synaptic plasticity, progressive neuronal loss and astrocytosis resulting in an early neurodegenerative phenotype, has been demonstrated [17].

The TBA2.1 mouse line described by Alexandru et al. and other lines, namely TBA2 [18] and FAD42 [19] use truncated $A \beta$ constructs with an $E$ to $Q$ substitution at position 3 of the $A \beta$ peptide. The $\mathrm{N}$-terminal $\mathrm{Q}$ residue of the used $A \beta(Q 3-42)$ construct is the preferred substrate for $\mathrm{QC}$, but it shows a higher rate of spontaneous cyclization, compared to the endogenous $A \beta$ species with $\mathrm{E}$ at position $3[2,3]$.

In line with this research, several new transgenic (tg) ETNA ( $E$ at the truncated N-terminus of $A \beta$ ) mouse models were generated using a truncated, but nonmutated and therefore more physiological $A \beta(E 3-42)$ construct to analyze endogenous $\mathrm{A} \beta(\mathrm{pE} 3-42)$ formation in vivo.

ETNA mice were intercrossed with tg mice overexpressing human $\mathrm{QC}$ (hQC) to further investigate the role of $\mathrm{QC}$ in $\mathrm{pE} 3-\mathrm{A} \beta$ formation in vivo. Interestingly, these newly generated mouse lines show significant neuronal loss in striatum, substantiating the hypothesis of modified $A \beta$ as crucial molecular player in neurodegeneration.

\section{Methods}

\section{Experimental animals}

Tg ETNA mice were generated by chromosomal integration of an expression cassette as described for TBA2.1 and TBA2.2 [17]. In brief, murine Thy1.2 regulatory sequences flank the coding sequence for a fusion protein consisting of the pre-pro peptide of murine thyrotropinreleasing hormone (TRH, Thyroliberin) fused to the $\mathrm{N}$ terminus of the truncated human $A \beta(3-42)$ and directs expression into neuronal tissue [20]. The regulatory elements prohormone convertase $(\mathrm{PC})$ cleavage within the trans-Golgi and secretory vesicles liberates $A \beta(3-42)$ preferentially within the secretory pathway, where they are modified by QC activity [21,22].

Similarly, tg hQC mice were generated by integration of a Thy1.2 expression cassette containing the coding sequence of hQC (NM_012413) into the chromosome of CBA/C57BL/6 hybrid embryos. F1 tg animals which yielded strong genomic southern blot hybridization signals, using labeled expression cassette probes, were selected for colony expansion and backcrossed to C57BL/6 wildtype (wt) animals. Transgene expression levels in the established colonies were characterized by real-time quantitative reverse transcription PCR (qRT-PCR). The mouse lines E5, E8, and hQC displayed high transgene transcription rates and were selected for phenotypic analysis.

The following genotypes of $\mathrm{tg}$ and control animals were used (Table 1). Heterozygous (het) and homozygous (hom) E5 were compared to wt littermates. E8 het and E8 hom were compared to wt littermates. By intercrossing E5 and E8, double heterozygous E85 het/het were generated and compared to wt/wt littermates.

E8 and E85 were intercrossed with hQC to generate multi-tg E8-hQC and E85-hQC. In the genotype description of multi-tg ETNA-hQC animals, the hQC allele is always indicated last. E8-hQC hom/wt, hom/het, and hom/hom were compared to wt/wt littermates. E85hQC always refers to het/het for the E85 alleles and both wt and hom of the hQC allele were used. As no gender differences were observed in these lines, both male and female animals were used in this study. For all experiments, mice of the age 1 to 14 months were used, while the maximum age difference in one group was 7 days.

\section{Animal care}

Laboratory animal care and experiments were conducted in accordance with the German animal protection act and the regulations of the government of Upper Bavaria (Regierung Oberbayern; permission TVA 55.2-1-54-2531135-07). In this proposal the role of the enzyme QC in the development of AD should be investigated. Thereby the question should be addressed, if a genetic modulation of $\mathrm{A} \beta$ or a pharmacological inhibition of QC-activity can 
Table 1 Genotypes of transgenic animals

\begin{tabular}{lllcc}
\hline ETNA nomenclature & E8 & E5 & hQC \\
\hline E5 & wt & - & wt & - \\
E5 & het & - & het & - \\
E5 & hom & - & hom & - \\
E8 & wt & wt & - & - \\
E8 & het & het & - & - \\
E8 & hom & hom & - & - \\
E85 & wt/wt & wt & wt & - \\
E85 & het/het & het & het & - \\
E8-hQC & wt/wt & wt & - & wt \\
E8-hQC & hom/wt & hom & - & wt \\
E8-hQC & hom/het & hom & - & het \\
E8-hQC & hom/hom & hom & - & hom \\
E85-hQC & het/het/wt & het & het & wt \\
E85-hQC & het/het/hom & het & het & hom \\
\hline
\end{tabular}

Overview of used genotypes and nomenclature of ETNA models. Wildtype (wt), heterozygous (het), and homozygous (hom) animals of single transgenic E5 and E8 models were used.

For the double transgenic E85 model, the E8 and E5 models were crossbred and only double heterozygous (het/het) and wildtype (wt/wt) animals were used.

E8 and E85 animals were intercrossed with hQC animals to generate multi-tg ETNA-hQC animals. In these models the genotype of the hQC allele is always indicated last.

For the double transgenic E8-hQC model, In E8-hQC the E8 allele was always homozygous in hom/wt, hom/het, and hom/hom animals and wildtype (wt/ wt) animals were used as control.

For the triple transgenic E85-hQC model the E8 and E5 alleles were always double heterozygous (het/het) and wt, and hom of the hQC allele was used.

achieve a causal therapy of AD. Animal protocols were designed to minimize any pain and stress experienced by the animals. Prior to the study, the number of required animals was statistically determined and not exceeded during the experiments. Number of animals and all animal protocols were specifically approved by the governmental animal ethics committee of Upper Bavaria. Health and immune status of all experimental animals was constantly monitored.

\section{Animal housing and husbandry}

All mice were maintained in individually ventilated cages (IVC; Tecniplast, cage Euro-standard Type II L) animal units in a temperature $\left(22+/-2^{\circ} \mathrm{C}\right)$ and humidity $(55+/-$ $10 \%$ ) controlled facility with a $12 \mathrm{~h} \mathrm{light/dark} \mathrm{cycle} \mathrm{(lights}$ on at 6 a.m.), using standard sterile bedding and had access to standard laboratory pellets (ssniff Spzialdiät) and water ad libitum.

\section{Preparation of brain tissue}

Mice were transferred to the preparation laboratory, deeply anesthetized with carbon dioxide, and transcardially perfused with phosphate-buffered saline (PBS). Brains were removed from the skull and sagitally bisected. Both hemispheres were used for different analyses to reduce the number of used animals and to correlate neurodegeneration and protein levels per animal. Left hemispheres were snap-frozen in liquid nitrogen and stored at $-80^{\circ} \mathrm{C}$ for analysis of enzyme activity, mRNA or protein levels. Right hemispheres were cut into sample pieces and immersion-fixed in IHC Zinc Fixative (BD Pharmingen) according to the manufacturer's protocol.

\section{Genetic characterization of transgenic models}

Mapping of the chromosomal transgene integration sites for ETNA and hQC lines was performed as described before [23] using the Genome Walker Universal Kit (Clontech). ETNA transgene expression levels were assessed by qRT-PCR. In brief, brain biopsies were homogenized in QIAzol reagent (Qiagen) using an Ultra Turrax disperser (Sigma) and, after centrifugation, total RNA was further purified from the aqueous phase using RNeasy spin columns (Qiagen). $1 \mu \mathrm{g}$ RNA was reverse transcribed using oligodT primers and Superscript II (Invitrogen) according to manufacturer's instructions. PCR reactions were performed in duplicates using $1 \mu \mathrm{l}$ of resulting cDNA per $20 \mu \mathrm{l}$ reaction volume containing QuantiTect SYBR Green PCR Master Mix (Qiagen). The housekeeping gene beta-actin (ACTB) was used as control. Two ETNA transgene-specific primer sets were used for PCR amplification with one set containing primer pairs 5'-AAACGCCAATTCCGACAT-3' (forward) and $5^{\prime}$-GAAGGACCTCGAGTTACGC-3' (reverse), and the other set containing primers $5^{\prime}$-CTCTTGGCAC CTAGAGGATCT-3' (forward) and 5' -AAGGTCAGGA GTCACAGCAC-3' (reverse). Primers for amplification of the human QC transcript were 5'-ACCCTCAAT CCCACTGCTAA-3' (forward) and 5'-CTGGCTTGGA GTCTGAAACA-3' (reverse). Primers for mouse ACTB were purchased from Qiagen. PCR was performed on a LightCycler instrument (Roche) according to preset protocol and mRNA levels were analyzed by the $\Delta \Delta \mathrm{Ct}$ method.

\section{ELISA analysis of total $A \beta$ and $p E 3-A \beta$ protein levels}

Hemisected brains were homogenized in $2.5 \mathrm{ml}$ of TBS by means of a Precellys homogenizer (Peqlab) followed by sonication for $3 \times 10 \mathrm{~s}$. The resulting homogenate was centrifuged at $75,000 \times \mathrm{g}$ for $1 \mathrm{~h}$ at $4^{\circ} \mathrm{C}$. The supernatant was stored at $-80^{\circ} \mathrm{C}$ and $\mathrm{A} \beta$ peptides were further extracted with $1 \mathrm{ml}$ of $70 \%$ formic acid (FA). The solution was neutralized by addition of a Tris base solution $(3.5 \mathrm{M})$ and further diluted by $6.05 \mathrm{ml}$ of ELISA blocker solution (Pierce). The TBS and FA fractions were subjected to $A \beta(x-42)$ and $A \beta(p E 3-42)$ ELISA (IBL International). ELISA analysis was performed according to the manufacturer's instructions. Following quantification, the 
$\mathrm{A} \beta$ content of both fractions (TBS and FA) was normalized to the brain wet weight.

\section{Enzyme activity analysis of QCs}

QC/isoQC activity was determined using a discontinuous assay, which is based on HPLC-UV. Tissue samples were homogenized in a buffer consisting of $10 \mathrm{mM}$ Tris, $100 \mathrm{mM} \mathrm{NaCl}, 5 \mathrm{mM}$ EDTA, 0.5\% Triton X-100 and $10 \%$ Glycerol, pH 7.5, using a Precellys homogenizer (Peqlab). Reaction samples consisted of $50 \mu \mathrm{M}$ Q- $\beta$ NA in $25 \mathrm{mM}$ MOPS, pH 7.0, $0.1 \mathrm{mM}$ N-ethylmaleinimide and enzyme solution in a final volume of $1 \mathrm{ml}$. The reaction temperature was $37^{\circ} \mathrm{C}$. Test samples were removed for up to $1 \mathrm{~h}$, and the reaction was stopped by boiling for $5 \mathrm{~min}$. The supernatant was applied to HPLC analyses on a RP18 LiChroCART HPLC Cartridge. The substrate Q- $\beta N A$ and the pE- $\beta N A$ were separated by increasing concentration of acetonitrile in water containing $0.1 \%$ TFA. The concentration of $\mathrm{pE}-\beta \mathrm{NA}$ was determined from a standard curve determined under assay conditions.

\section{Primary screening of general health and behavior}

Semi-quantitative characterization of general health, neurological reflexes and sensory functions was achieved by monthly application of a battery of assays generally referred to as the SHIRPA screening protocol [24]. These consistied in primary screening of muscle and lower motor neuron functions, spinocerebellar, sensory, neuropsychiatric, and autonomic functions. Primary screening provides a behavioral and functional profile by observational assessment, suitable for detecting phenotypes that could interfere with further behavioral assays. Highly standardized primary screens were applied by trained observers blinded to the genotype of the animals and were initiated with observing social behavior in the home cage (home cage observation) subsequently followed by monitoring of undisturbed behavior of single animals in a clear plexiglass arena for $90 \mathrm{~s}$ (individual observation). This analysis was followed by a battery of simple behavioral assays characterizing the acoustic startle reflex, hanging behavior, visual placing, falling behavior, righting reflex, postural reflex, negative geotaxis, hanging wire, ear twitch, whiskers twitch, and eye blink, as well as assessment of dysmorphology and body weight [25].

\section{Automated phenotyping analysis of locomotor activity} Circadian patterns of locomotor activity were assessed using the PhenoMaster system (TSE Systems). Two horizontally staked infrared-sensor frames detected locomotion in the horizontal axis, and rearing events in the vertical axis. Continuous recording of these parameters was carried out simultaneously for all mice in individual observation units (standard type III cages with grid lid) for $136 \mathrm{~h}$ or $44 \mathrm{~h}$, starting at 2 p.m. Data was collected automatically with a rate of $100 \mathrm{~Hz}$ and stored on a personal computer as a sum over $1 \mathrm{~min}$ intervals. The observations took place under a 12-h light/dark-cycle (lights on at 6 a.m.; lights out at 6 p.m.). Animals received water and food ad libitum and remained undisturbed by the investigator during observation.

\section{Acoustic startle response and prepulse inhibition}

The experimenter was blinded to the genotype of the animals. Female E85 mice were placed in random order in a startle chamber (TSE Systems) and habituated for $30 \mathrm{~s}$ with $68 \mathrm{~dB}$ white noise. 10 baseline startle trials with $120 \mathrm{~dB}$ white noise were conducted and reactivity was measured in changes of pressure on the floor plate. Baseline determination was followed by prepulse inhibition (PPI) test consisting of 62 randomized trials (10 startle trials: $20 \mathrm{~ms}$ of $120 \mathrm{~dB}$ white noise; $4 \times 10$ prepulse + startle trials: $20 \mathrm{~ms}$ of white noise preceded $100 \mathrm{~ms}$ by $20 \mathrm{~ms}$ of $72 \mathrm{~dB}, 76 \mathrm{~dB}, 80 \mathrm{~dB}$, or $84 \mathrm{~dB}$ white noise; $4 \times 3$ control trials: 20 ms of $72 \mathrm{~dB}, 76 \mathrm{~dB}, 80 \mathrm{~dB}$, or $84 \mathrm{~dB}$ white noise followed by $100 \mathrm{~ms}$ of $68 \mathrm{~dB}$ white noise).

\section{Immunohistochemical studies}

Immersion-fixed brains were dehydrated, embedded in low-melting-point paraffin (DCS Innovative Diagnostic Systems) and sectioned at $8 \mu \mathrm{m}$ on a rotating microtome. After deparaffinization, sections were incubated with the primary antisera overnight at $4^{\circ} \mathrm{C}$. For immunodetection, a biotinylated species-specific IgG secondary antibody was used, followed by signal enhancement with an avidin-biotin-complex (Vectastain ABC Kit; PK-6100; Vector Laboratories) and visualized by peroxidase reactivity (ImmPACT Peroxidase Kit; SK-4105; Vector Laboratories).

In double fluorescent immunolabeling procedures, secondary antibodies were $\mathrm{Cy}$-2- or Cy-3-coupled speciesspecific IgGs.

In this study $\mathrm{A} \beta$-specific antibody $6 \mathrm{E} 10$ (mouse monoclonal; SIG-39320; Covance; 1:10,000 dilution), pE3-A $\beta$-specific antibodies Abeta-pE3 (rabbit polyclonal; 218003; Synaptic Systems; 1:100,000 dilution) and Abeta-pE3 (mouse monoclonal; 218011; Synaptic Systems; 1:10,000 dilution), QC-specific antibody 1302 (rabbit polyclonal; Probiodrug; 1:1,000 dilution), and human QC-specific antibody 8696 (rabbit polyclonal, Probiodrug; 1:1,000 dilution), glia-specific antibody GFAP (rabbit polyclonal, Z0334; DAKOCytomation; 1:30,000 dilution), activated caspase 3-specific antibody (rabbit polyclonal, 9661, Cell Signaling Technology; dilution 1:100), neuron-specific antibody NeuN (mouse monoclonal; MAB377; ChemiconMillipore; 1:10,000 dilution), and DARPP32-specific antibody (rabbit monoclonal; 1710-1; Epitomics; 1:10,000 dilution) were used as primary antibodies. 
As secondary antibodies, biotinylated mouse-specific IgG (M.O.M. Kit; BMK-2202; Vector Laboratories; 1:500 dilution), biotinylated rabbit-specific IgG (goat, Vector Laboratories; 1:500 dilution), Cy-2-coupled rabbit-specific IgG (goat, Dianova; 1:250 dilution), Cy-3-coupled rabbitspecific IgG (goat, Dianova; 1:250 dilution), Cy-2-coupled mouse-specific IgG (goat, Dianova; 1:250 dilution), and Cy-3-coupled mouse-specific IgG (goat, Dianova; 1:250 dilution) were used.

\section{Semi-automated quantification with CellProfiler}

For quantification, $8 \mu \mathrm{m}$ coronal sections, of the right hemisphere, corresponding to stereotaxic levels bregma $0.14 \mathrm{~mm}$ to $0.38 \mathrm{~mm}$ (as defined in Paxinos and Franklin [26]) were used for analysis. To quantify $\mathrm{pE} 3-\mathrm{A} \beta$ positive cells, images including all stained striatal cells of $\mathrm{pE} 3-\mathrm{A} \beta$ stained slides were taken. To quantify neuronal numbers, parallel sections were stained with $\mathrm{NeuN}$ and a region of interest (ROI) was defined. Images were taken with the Picture Frame Application 2.3 (Optronics) using a Nikon Eclipse 80i microscope (Nikon Instruments) with a MicroFIRE2.3A camera (Optronics).

To count the number of stained cells, CellProfiler (CP) (r10997) software was used, which enables simultaneous high throughput measuring of size, shape, intensity and texture of cells [27]. A detailed protocol, definition of the ROI, both used 'pipelines', and raw data examples are provided as Appendix 1. Briefly, every image was inverted, converted from RGB to grayscale and stained cells were identified by contrast, shape, and size.

\section{Results}

\section{Transgenic integration}

Several tg mouse lines were generated and examined alone or in intercrosses in order to characterize QCdependent $\mathrm{pE} 3-\mathrm{A} \beta$ formation and neurotoxicity in vivo. The expression cassettes of ETNA lines consist of the pre-pro-sequence of murine TRH fused to the coding sequence of human $A \beta(3-42)$ (Figure 1A). Processing of the TRH sequence in the secretory pathway of neurons is facilitated by signal peptidases and PCs [28] leading to the preferential liberation of $A \beta(3-42)$ within the transGolgi network and secretory granules. Two independent tg lines (E5 and E8) were established to examine transgene dosage effects. By intercrossing both lines, double het/het animals were generated. These animals were termed E85 and examined in order to minimize data misinterpretation due to positional effects based on chromosomal transgene insertion.

In transgene integration mapping experiments for line E8, the 5' flanking region of the expression cassette was identified as part of a DNA repeat element, presumably on chromosome 6. This element is repeated eight times and therefore the exact localization of the expression cassette remains unknown. Attempts to isolate the 3 'flanking regions were not successful.

In line E5, the transgene cassette has integrated as multimer in a head-to-head orientation. The mapping experiments did not deliver any flanking chromosomal regions. However, the head-to-head orientation of the cassette allows differentiation of the E5 and E8 tg alleles in PCR-based genotyping assays.

Mapping experiments for mouse line hQC demonstrated that a 3 ' - integration of the expression cassette occurred on chromosome 13 (map position 89.0 Mbp; NCBI Build 36) in intron 1 of the mouse Edil3 gene (EGF-like repeats and discoidin I-like domains 3). PCR reactions on homozygote DNA with primer sets binding to regions upstream of the integration site showed that the integration event deleted a DNA region of about $50 \mathrm{~kb}$. Hence, integration of the expression cassette removed the first coding exon of Edil3 and hom animals are devoid of Edil3 gene function.

\section{Construct expression and processing}

Transgene expression was quantified using qRT-PCR analysis in those lines originating from the carefully selected founder lines. E5 and E8 show similar mRNA levels, with E5 expressing about 90\% of the transgene compared to E8 (data not shown).

ELISA analysis of protein levels revealed substantial amounts of total $\mathrm{A} \beta$ in E5, E85, and E8. At both 1 and 9 months of age, highest levels were detected in E8 and lowest in E5, while levels in E85 were intermediate (Figure $1 \mathrm{~B}$ ). Total $\mathrm{A} \beta$ levels detected by ELISA include all forms endogenic $A \beta$, the truncated $A \beta(3-42)$ construct, unprocessed mTRH prepro-A $\beta(3-42)$, and also any partially processed precursor molecules. Concentrations up to $2.5 \mathrm{mg} / \mathrm{g}$ were detected in the brains of hom E8, although the exact amount of present $A \beta$ could not be determined.

Showing distinct pyroglutamyl modification of the $\mathrm{N}$ terminally truncated $A \beta(3-42)$ peptide, significant levels of $\mathrm{pE} 3-\mathrm{A} \beta$ were detected in all 3 lines. At the age of 9 months these $\mathrm{pE} 3-\mathrm{A} \beta$ levels reflected a similar distribution pattern among genotypes as detected for total $A \beta$ levels (Figure 1C).

\section{General health and behavioral phenotype}

Monitoring of general health revealed an average litter size of all ETNA mouse lines (E5, E8, and E85) in accordance with the expectation from a C56BL/6 inbred background. Analysis of genotypes revealed a nearly Mendelian ratio of homozygous (hom), het, and wt genotypes (data not shown).

Analysis of survival revealed no significant differences between genotype groups for hom E8 (Figure 2A) and het/ het E85 (Figure 2B) mice until the age of 10 months, but showed a trend for higher mortality in both E8 and E85. 


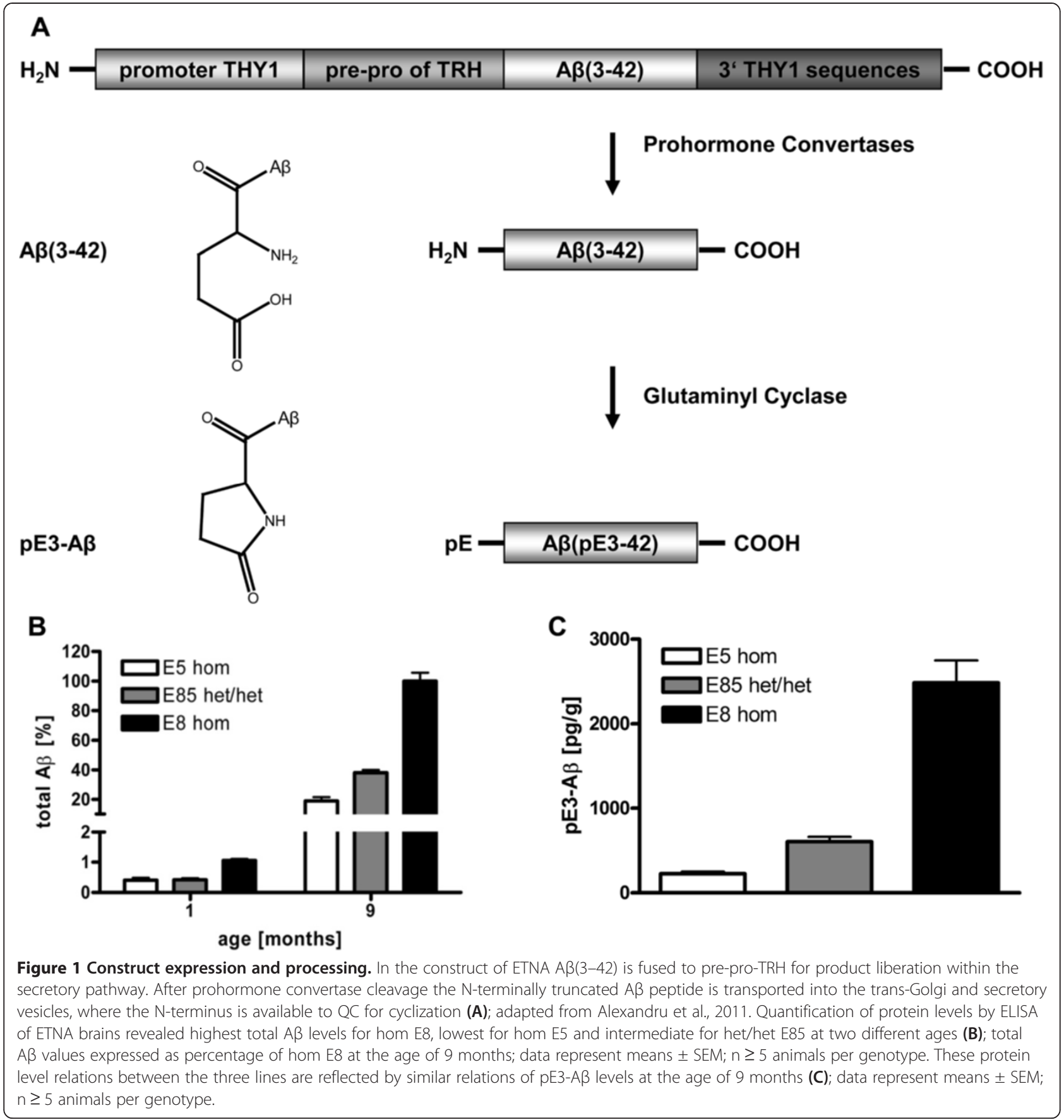

Measurement of weight revealed no significant differences between hom E8 (Figure 2C) or het/het E85 (Figure 2D) mice and wt littermates, respectively.

Monthly monitoring of general health, neurological reflexes and sensory functions in the primary screening showed no obvious alterations, with the exception of the acoustic startle reflex (see section acoustic reactivity and sensorimotor gating).

Various tests for basal physiological responses as well as in-depth characterization of emotionality, cognition, and pain perception revealed no significant differences (data not shown).

\section{Locomotor activity}

To analyze the circadian pattern of various behavioral parameters, ETNA mice were monitored using the automated PhenoMaster system. In this system, food and water consumption, as well as locomotor and rearing activity were recorded. None of the tested animals showed 


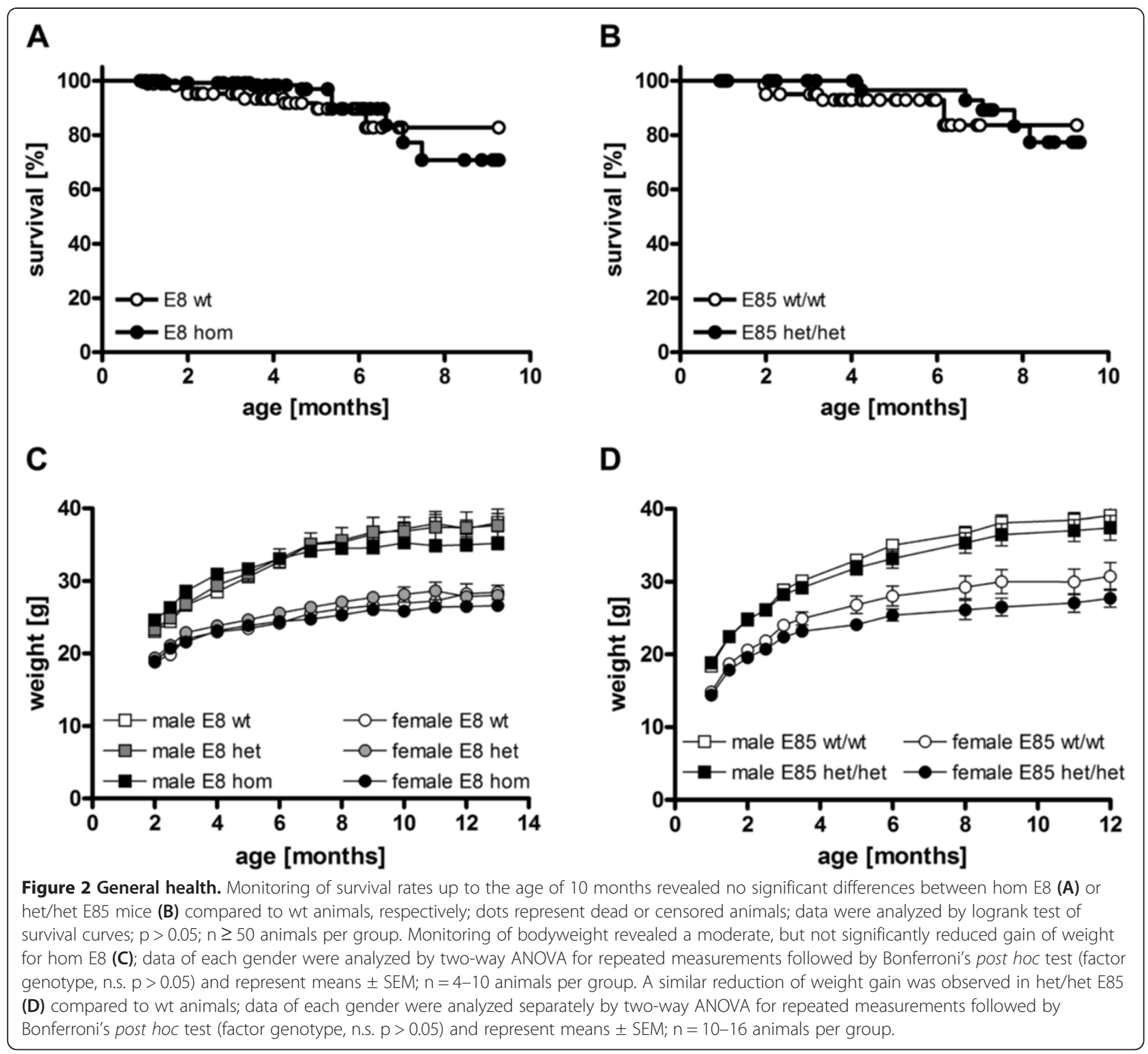

evidence of altered feeding or drinking behavior (data not shown).

In hom E8 mice aged 10 months, measurement of total distance moved within $136 \mathrm{~h}$ showed significantly increased locomotor activity compared to wt littermates (Figure 3A).

For a more detailed analysis, the locomotor activity of het/het E85 mice was regularly monitored. Beginning with an age of 4 months het/het E85 mice showed progressive hyperactivity alterations (data not shown). This elevated activity is significantly increased starting at the age of 6 months in het/het E85 mice (Figure 3B). At the age of 8 months the significant increase in total distance moved of het/het E85 animals is detectable after only $44 \mathrm{~h}$ of recording (Figure $3 \mathrm{C}$ ).

\section{Acoustic reactivity and sensorimotor gating}

Monitoring of E8 mice in the primary screening revealed an impaired reaction to a given acoustic signal beginning at the age of 2 months affecting 90\% of hom E8 animals at the age of 6 months (Figure 3D).

For a more detailed analysis het/het E85 mice were monitored monthly at the age of 2 to 10 months in the primary screening, which showed significantly increased percentages of affected animals compared to wt littermates (paired t-test of 9 time points, ${ }^{* * *} \mathrm{p}=0.007, \mathrm{n} \geq 22$ animals per genotype).

Importantly, 50\% of wt C57BL/6 mice showed reduced reactivity at the age of 10 months. This is attributable to an age-related hearing loss mutation in the $C d h 23^{a h l}$ gene $[29,30]$. Nonetheless, more than $90 \%$ of het/het 


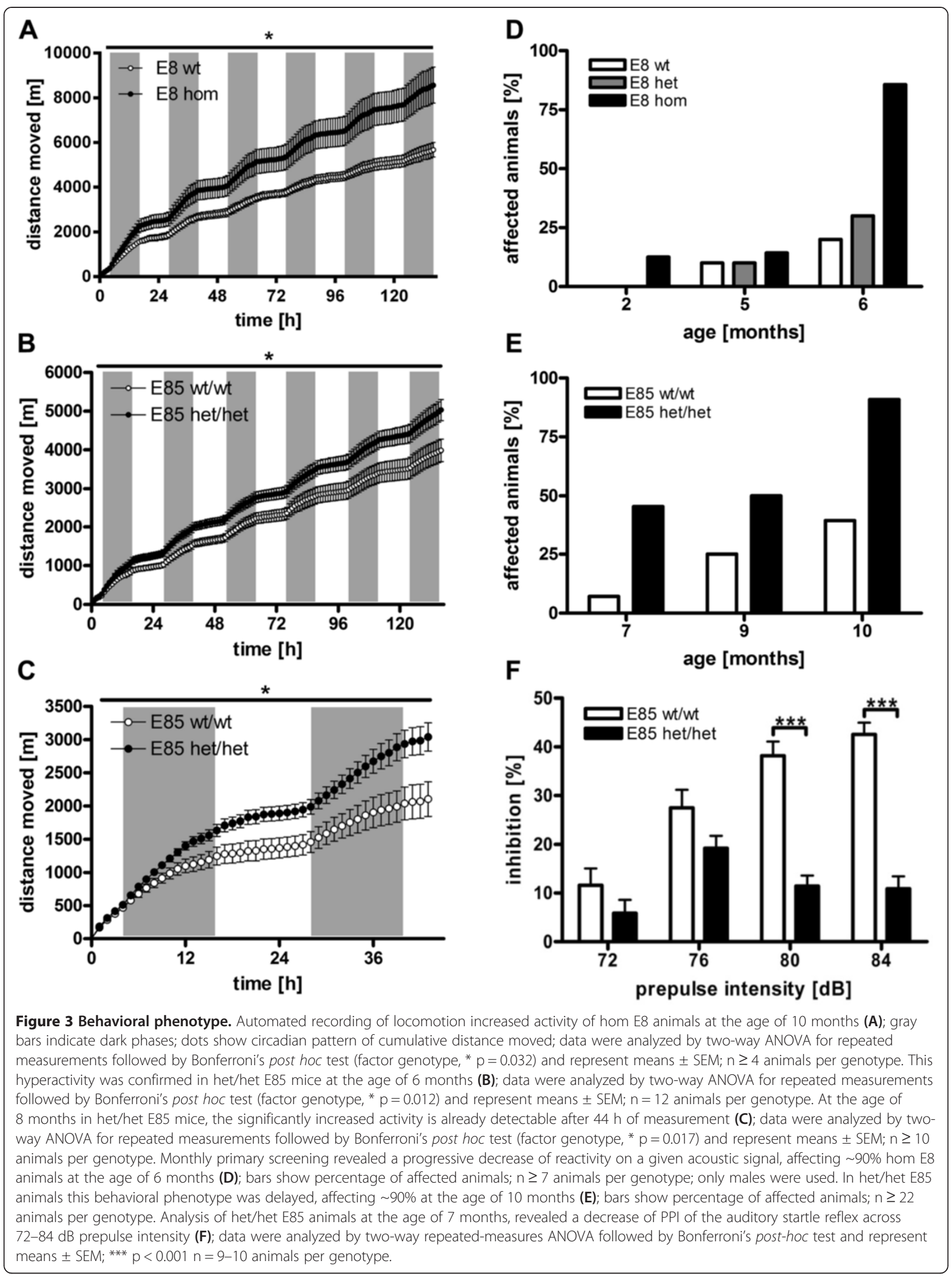


E85 animals were affected, arguing for impaired sensorimotor gating in these animals (Figure 3E).

To address the cause of reduced acoustic reactivity, PPI of het/het E85 mice was analyzed. The significant loss of PPI compared to wt animals indicates impaired sensorimotor gating (Figure 3F).

\section{Expression of the transgenic product $A \beta(3-42)$}

To identify the expression pattern of the $\mathrm{tg}$ product A $\beta(3-42)$, coronal E5 and E8 brain sections from different brain regions and at different ages were stained with the anti-A $\beta$ antibody $6 \mathrm{E} 10$. This histopathological analysis revealed an early expression of the construct in different brain regions, with most prominent expression in the striatum.

High immunoreactivity was also detected in amygdala (Additional file 1: Figure S1B) and single 6E10 positive cells were found in cortex and brainstem (Additional file 1:
Figure S1D, E) up to the age of 9 months in ETNA animals.

In all ETNA lines, the striatal 6E10 signal is intraneuronally colocalized with $\mathrm{pE} 3-\mathrm{A} \beta$ reactivity (Figure $4 \mathrm{~A}$ ). $6 \mathrm{E} 10$ reactivity was observed in the pyramidal cell layer of the hippocampus of ETNA mice Additional file 1: Figure S1C) but up to the age of 9 months (latest time point of analysis) no $\mathrm{pE} 3-\mathrm{A} \beta$ formation was found (data not shown).

Double immunofluorescent labeling of striatal sections revealed mouse QC (mQC)-specific immunoreactivity in $\mathrm{pE} 3-\mathrm{A} \beta$ positive cells, suggesting $\mathrm{QC}$-dependent $\mathrm{pE} 3-\mathrm{A} \beta$ formation (Figure 4B).

To further analyze neuropathology, GFAP staining was performed and revealed activated astroglia in the vicinity of $\mathrm{pE} 3-\mathrm{A} \beta$ positive neurons, indicating neuroinflammatory processes in the lateral striatum of ETNA animals (Figure 4C).
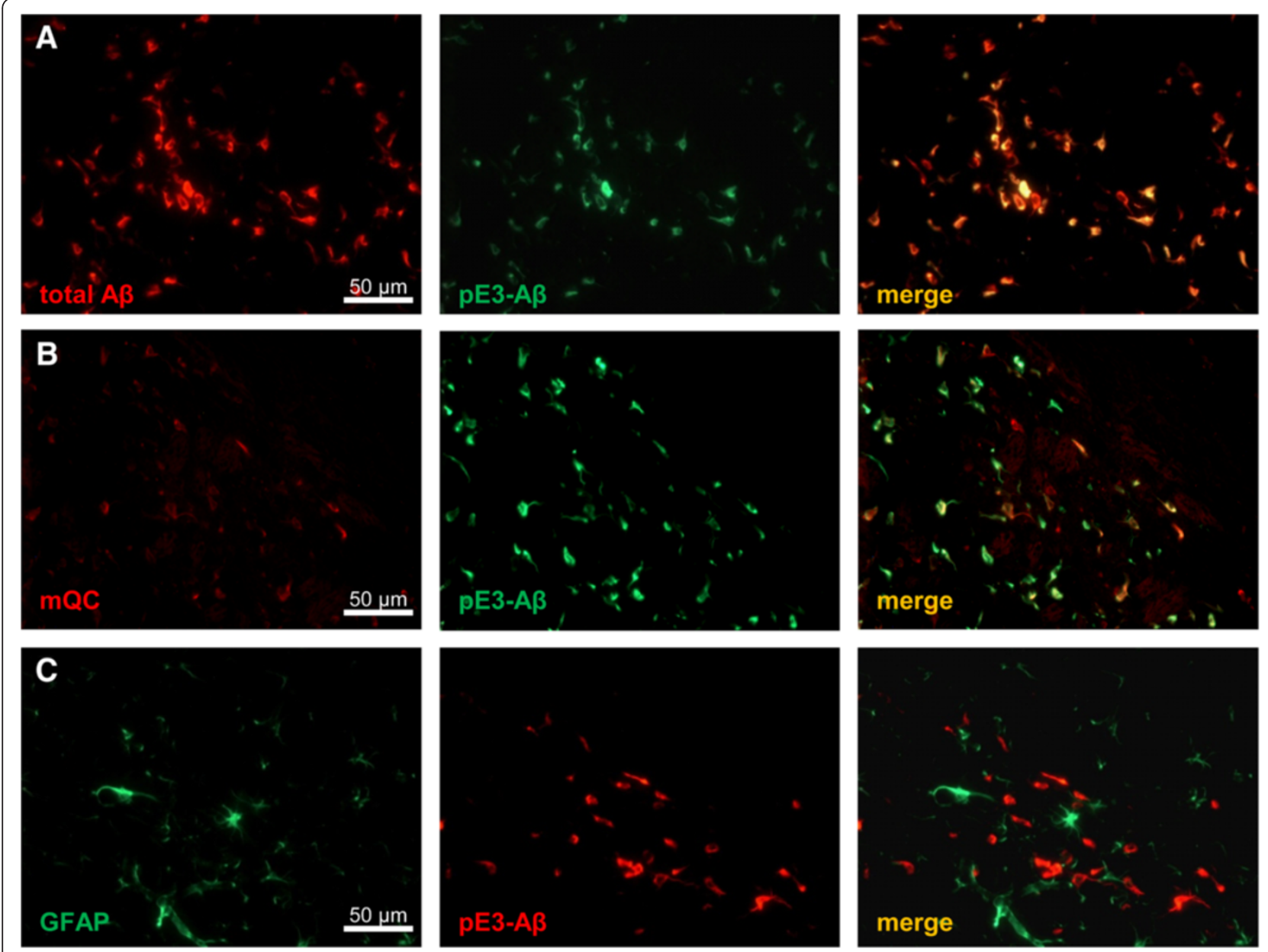

Figure 4 Striatal (co-)localizations of $\mathbf{A} \boldsymbol{\beta}, \mathrm{pE} 3-\mathbf{A} \boldsymbol{\beta}, \mathbf{Q C}$ and astroglia in lateral striatum. Double immunofluorescent labeling of total $A \beta$ (red) and $p E 3-A \beta$ (green) revealed intraneuronal colocalization of tg product and $p E$-modified $A \beta$ in the lateral striatum of hom E8 animals (A). Double immunofluorescent labeling of the lateral striatum showed $\mathrm{MQC}$-specific immunoreactivity (red), which is colocalized with pE3-A ( $\mathrm{green}$ ) in hom E8 animals (B). Double immunofluorescent labeling revealed increased GFAP reactivity (green) of activated astroglia in the vicinity of pE3-A $\beta$ positive cells (red) in the lateral striatum of hom E8 animals (C). 


\section{Kinetics}

To analyze the kinetics of neuropathology, protein levels were quantified by ELISA and the striatum of E5, E85, and E8 mice were stained with markers for $A \beta$ species, neuroinflammation, neurodegeneration, and dopamineand cAMP-regulated phosphoprotein of $32 \mathrm{kDa}$ (DARPP32) across age. In hom E8 animals, progressive pE3-A $\beta$ formation and neurodegenerative processes are observed from the age of 3 months, while E5 and E85 mice show delayed kinetics (data not shown).

Brains of hom E8 animals were analyzed in more detail at the age of $1,3,6,9$, and 12 months and compared to wt animals (Figure 5).

Expression of the $A \beta$ construct in the striatum can already be visualized starting at the age of 1 month with increasing signal up to 9 months (Figure 5A), whilst $\mathrm{pE} 3-\mathrm{A} \beta$ is detected from 3 months of age (Figure $5 \mathrm{~B}$ ). Quantification of $\mathrm{pE} 3-\mathrm{A} \beta$ positive cells revealed an exponential increase from 3 to 9 months (Figure 5G).

Staining with GFAP revealed activated astroglia in regional and temporal correlation of $\mathrm{pE} 3-\mathrm{A} \beta$ positive cells until the age of 9 months, while at 12 months the whole striatum shows extensive neuroinflammation (Figure $5 \mathrm{C}$ ).

Activated caspase 3 signal progressing from the age of 3 months suggests $\mathrm{pE} 3$-A $\beta$-associated apoptotic processes in the lateral striatum of hom E8 animals (Figure 5D).

Progressive decrease of DARPP-32 reactivity of neuropil in the same region was detected starting at the age of 6 months (Figure 5E), while intraneuronal immunoreactivity seemed to be unaffected (data not shown).

These neurodegenerative processes ultimately resulted in decreased numbers of NeuN positive cells indicating striatal cell loss beginning in at the age of 6 months (Figure 5F).

Quantification of protein levels by ELISA of whole E8 brain hemispheres revealed weak construct expression in juvenile animals, while from 3 to 12 months total $A \beta$ is comparatively robust (Figure $5 \mathrm{H}$; white bars).

Levels of $\mathrm{pE} 3-\mathrm{A} \beta$ are detectable from the age of 6 months rising until 9 months (Figure $5 \mathrm{H}$; black bars).

The protein levels are in line with histopathological analysis of striatum, highlighting the striatum as the region with the strongest alterations in the ETNA mouse model.

Reductions of protein levels and immunoreactive cells of total $A \beta$ and $p E 3-A \beta$ at 12 months seem to be caused by the lack of construct-expressing and $\mathrm{pE} 3-\mathrm{A} \beta$-forming neurons in the degenerated striatum of homozygous E8 animals.

\section{QC overexpression}

To analyze the influence of $\mathrm{QC}$ on $\mathrm{pE}-\mathrm{A} \beta$ and neuropathology, E8 and E85 animals were intercrossed with mice overexpressing human $\mathrm{QC}(\mathrm{hQC})$ generating ETNAhQC mice.

Staining of striatal brain sections of E8-hQC animals with specific hQC antibody confirmed intraneuronal coexpression of hQC and pE3-A $\beta$ (Figure 6A).

While endogenous QC-activity is constant in aging ETNA mice and shows the same levels as wt control animals (data not shown), het overexpression of hQC leads to a $\sim 5$ fold increase and hom overexpression to an $\sim 10$ fold increase of QC activity in the brains of ETNA animals (Figure 6B).

ETNA hom and ETNA-hQC hom/wt showed indistinguishable total $A \beta$ levels, $\mathrm{pE} 3-\mathrm{A} \beta$ levels, and striatal neuropathology confirming that the genetic background of hQC wt animals had no influence on $\mathrm{pE} 3-\mathrm{A} \beta$ formation or neurodegeneration (data not shown).

\section{Influence of hQC overexpression on $\mathrm{pE}-\mathrm{A} \beta$ formation}

Already at the age of 3 months, enhancing QC activity in hom E8 animals lead to a gene dosage-dependent increase of striatal pE3-A $\beta$ positive cells (Figure 7A) which was obvious at 6 months of age (Figure 7B).

As expected, quantification of $\mathrm{pE} 3-\mathrm{A} \beta$ positive cells revealed a significant increase in E8-hQC and E85-hQC mice (Figure 7C).

Quantification of $\mathrm{pE} 3-\mathrm{A} \beta$ levels by ELISA revealed similar distribution, but E85-hQC animals showed a more than 10 fold increase of $\mathrm{pE} 3-\mathrm{A} \beta$ protein value compared to E85 mice (Figure 7D).

Overexpression of hQC had no influence on total $A \beta$ levels detected by ELISA in both ETNA-hQC lines (data not shown) arguing for $\mathrm{QC}$-dependent $\mathrm{pE} 3-\mathrm{A} \beta$ formation in the ETNA mouse model.

\section{Influence of hQC overexpression on neuropathology}

To analyze the influence of hQC overexpression on neuropathology, double $\mathrm{tg} \mathrm{E} 8 \mathrm{-hQC}$ mice at the age of 6 months were stained with neurodegenerative and neuroinflammatory markers and striatal cell loss was quantified (Figure 8).

Although hom E8 animals showed obvious striatal neuroinflammation compared to wt animals, GFAP reactivity seemed to be enhanced by overexpression of hQC (Figure 8A).

Low DARPP-32 reactivity in striatum of homozygous E8 brain sections was further decreased by overexpression of hQC (Figure 8B).

Neuron-specific staining with NeuN-antibody of E8-hQC mice showed hQC dependent decrease of immunoreactivity (Figure $8 \mathrm{C}$ ). To further analyze the influence of hQC overexpression on neurodegeneration, a region of interest (ROI) was defined in the lateral striatum (Figure 8D) and neuronal numbers were quantified. 


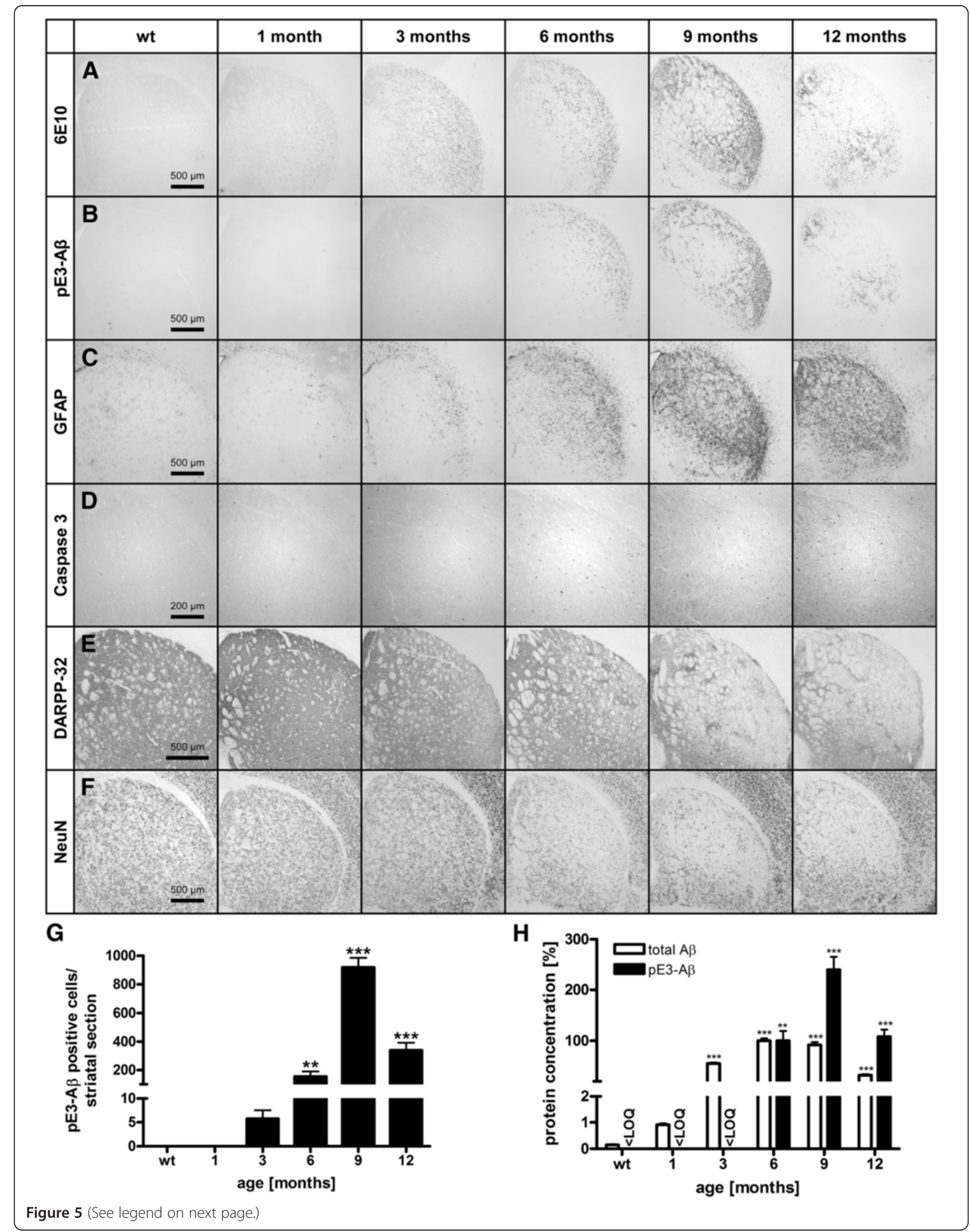


(See figure on previous page.)

Figure 5 Kinetics of homozygous E8 mice. Immunohistochemical analysis of hom E8 animals from the age of 1-12 months compared to wt animals (A-F). Staining with 6 E10 revealed progressive increase of total A 3 immunoreactivity from the age of 1-9 months with a decline at 12 months (A). Increase of pE3-A $\beta$ reactivity from 3-9 months and decline at 12 months (B) is accompanied by GFAP reactivity (C). Apoptotic processes are indicated provided by progressive caspase 3 activity beginning at the age of 3 months (D). The lateral striatum shows a progressive decrease of DARPP-32 reactivity of neuropil from the age of 6 months (E). The different processes result in decreased NeuN positive cells of E8 animals indicating cell loss beginning in at the age of 6 months $(\mathbf{F})$. Quantification of $p E 3-A \beta$ positive cells in the striatum of hom E8 animals revealed exponential increase from 3-9 months and declining numbers at the age of 12 months to the level of 6 months (G); data were analyzed by one-way ANOVA followed by Newman-Keuls post-hoc test and represent means \pm SEM; ${ }^{* *} p<0.01 ; *^{* *} p<0.001 ; n=4-8$ animals per group. Quantification of protein levels by ELISA of hom E8 brains revealed an progressing increase of total A $\beta$ until the age of 6 months; $D E 3-A \beta$ protein levels are detectable from the age of 6 , reaching its maximum at the age of 9 and declining at 12 months $(\mathbf{H})$; protein values are expressed as percentage of hom E8 brains at the age of 6 months; data were analyzed by one-way ANOVA followed by Newman-Keuls post-hoc test and represent means $\pm \mathrm{SEM} ;{ }^{* *} \mathrm{p}<0.01 ;{ }^{* * *} \mathrm{p}<0.001 ; \mathrm{n}=3-9$ animals per group; $<\mathrm{LOQ}$ (below level of quantification).

Quantification of neurons in the ROI of 6 months old E8-hQC mice revealed a significant increase of neuronal loss from $21 \%$ for hom/wt to $45 \%$ for hom/hom compared to wt animals (Figure 8E).

\section{Discussion}

Numerous studies support a gain of toxic function of $A \beta$ due to post-translational modifications such as isoaspartate formation, nitrosylation [31], and formation of pyroglutamate $[10,11,30,32]$. In order to assess the pathological consequence of enhanced $\mathrm{pE}-\mathrm{A} \beta$ in vivo, several tg mouse models expressing truncated human $A \beta$ with an $N$ terminal Q to E substitution have been generated [17-19]. Although these models display differences in terms of behavior and neuronal loss, they commonly suggested that an increase of $\mathrm{pE}-\mathrm{A} \beta$ enhances neuronal dysfunction. With regard to TBA2 and TBA2.1 mouse models, the ETNA gene product is the same. However, $\mathrm{pE3}-\mathrm{A} \beta$ formation in ETNA is not accelerated by an exchange of E by $Q$ at position 3 of $A \beta$. As shown in previous studies, the $\mathrm{N}$ terminal $\mathrm{E}$ residues represent worse substrates for QC (and isoQC) compared to $\mathrm{Q}$, and $\mathrm{E}$ residues should not cyclize spontaneously considering a half-life of $10-40$ years in vivo [2,3]. In accordance with such slower formation of $\mathrm{pE}-\mathrm{A} \beta(3-42)$ also in vivo, we observed the behavioral changes and neuronal loss at a later time point compared to TBA2.1.

Furthermore, in ETNA the tg product, $A \beta(3-42)$, is mainly expressed in the lateral striatum compared to the hippocampal and brainstem expression in TBA2.1. In this
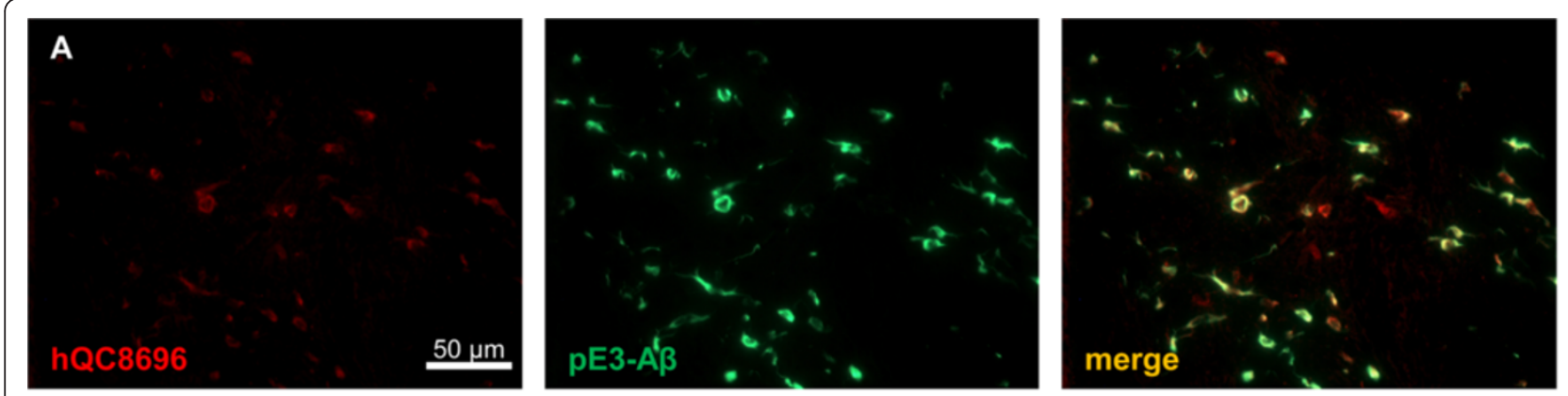

B

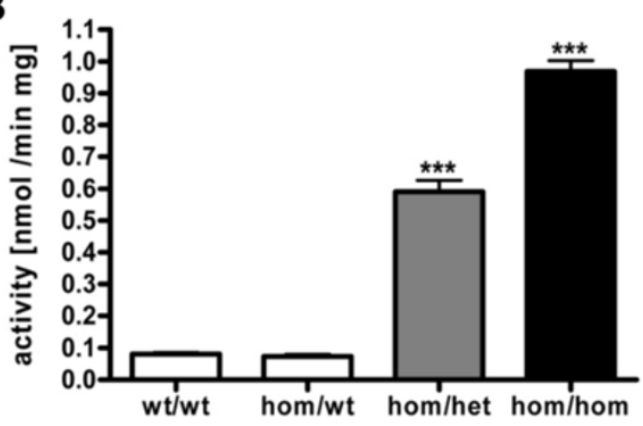

Figure 6 QC overexpression. Double immunofluorescent labeling of hom/hom E8-hQC animals revealed human QC specific immunoreactivity (red) colocalized with pE3-A (green) in the striatum (A). Analysis of QC activity at the age of 6 months revealed an indistinguishable activity for ETNA animals compared to wt animals and a $\sim 60$-fold increase for het and $\sim 100$-fold increase for hom overexpression of hQC (B); data were analyzed by one-way ANOVA followed by Newman-Keuls post-hoc test and represent means \pm SEM; ${ }^{* *} p<0.01 ; n=2-12$ animals per group. 


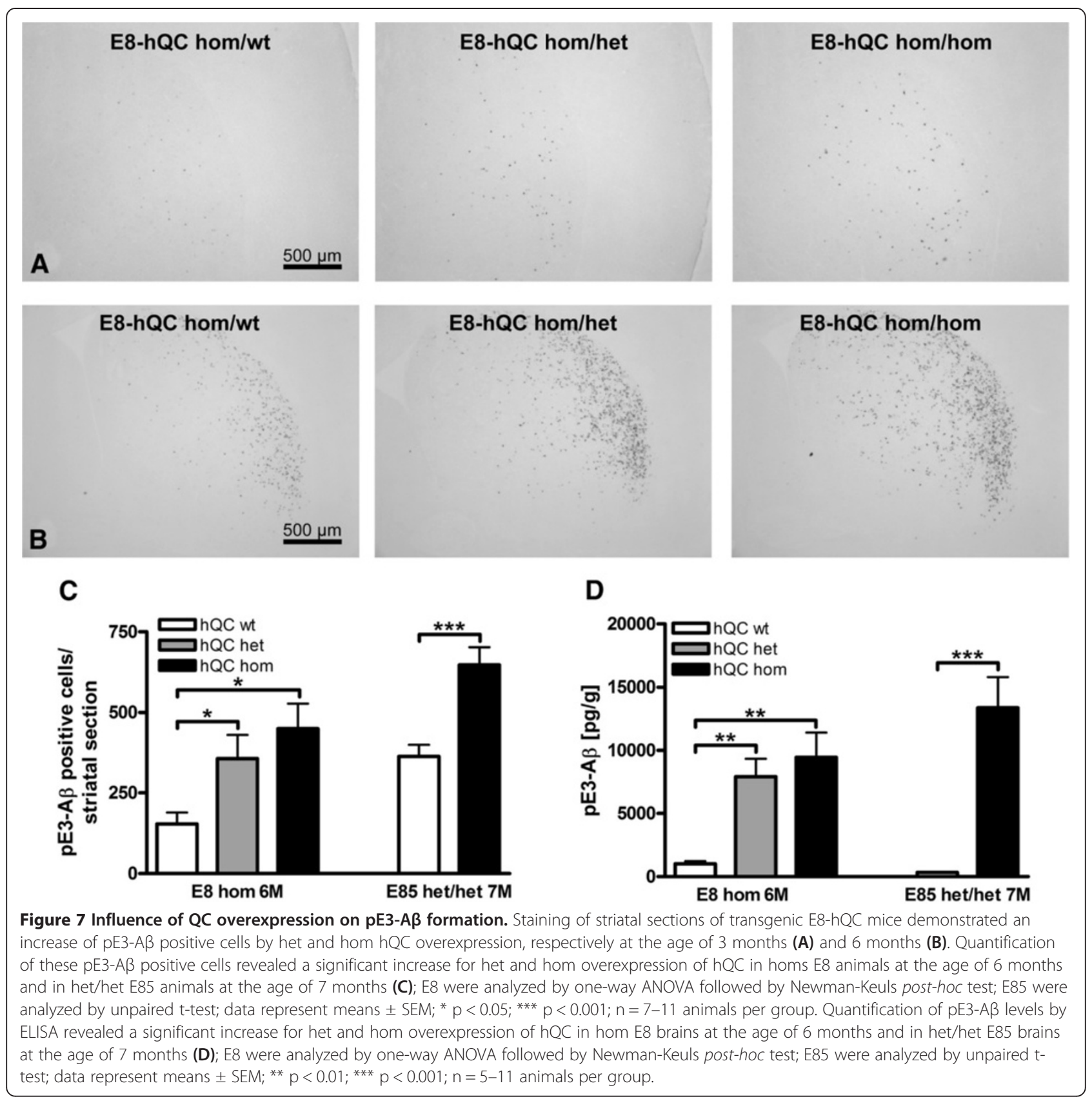

brain region ETNA animals show progressive intraneuronal $\mathrm{pE} 3-\mathrm{A} \beta$ formation associated with neuroinflammatory, apoptotic, and neurodegenerative processes, including but not limited to a reduced DARPP-32 immunoreactivity. The behavioral phenotype of single tg ETNA mice, hyperactivity and impaired acoustic sensorimotor gating, is associated with striatum the brain region with distinct neuropathology.

Key feature of the neuropathological process is a progressive site-specific expression of $\mathrm{pE} 3-\mathrm{A} \beta$, which is associated with increased caspase 3 and GFAP expression, ultimately resulting in significant cell loss of mediumsized spiny neurons (MSN), the major cell type in the striatum [33].

Interestingly, TBA2.1 mice have also shown expression of the $A \beta(Q 3-42)$ construct in the striatum and hippocampus. Only in the latter brain region, $\mathrm{pE} 3-\mathrm{A} \beta$ formation and neurodegeneration is observed in these animals [17]. ETNA mice, which use the same Thy1.2 promoter and expression cassette and only differ in one amino acid, express the $A \beta(E 3-42)$ construct in the same regions, but surprisingly $\mathrm{pE} 3-\mathrm{A} \beta$ formation and neurodegeneration mainly occurs in 


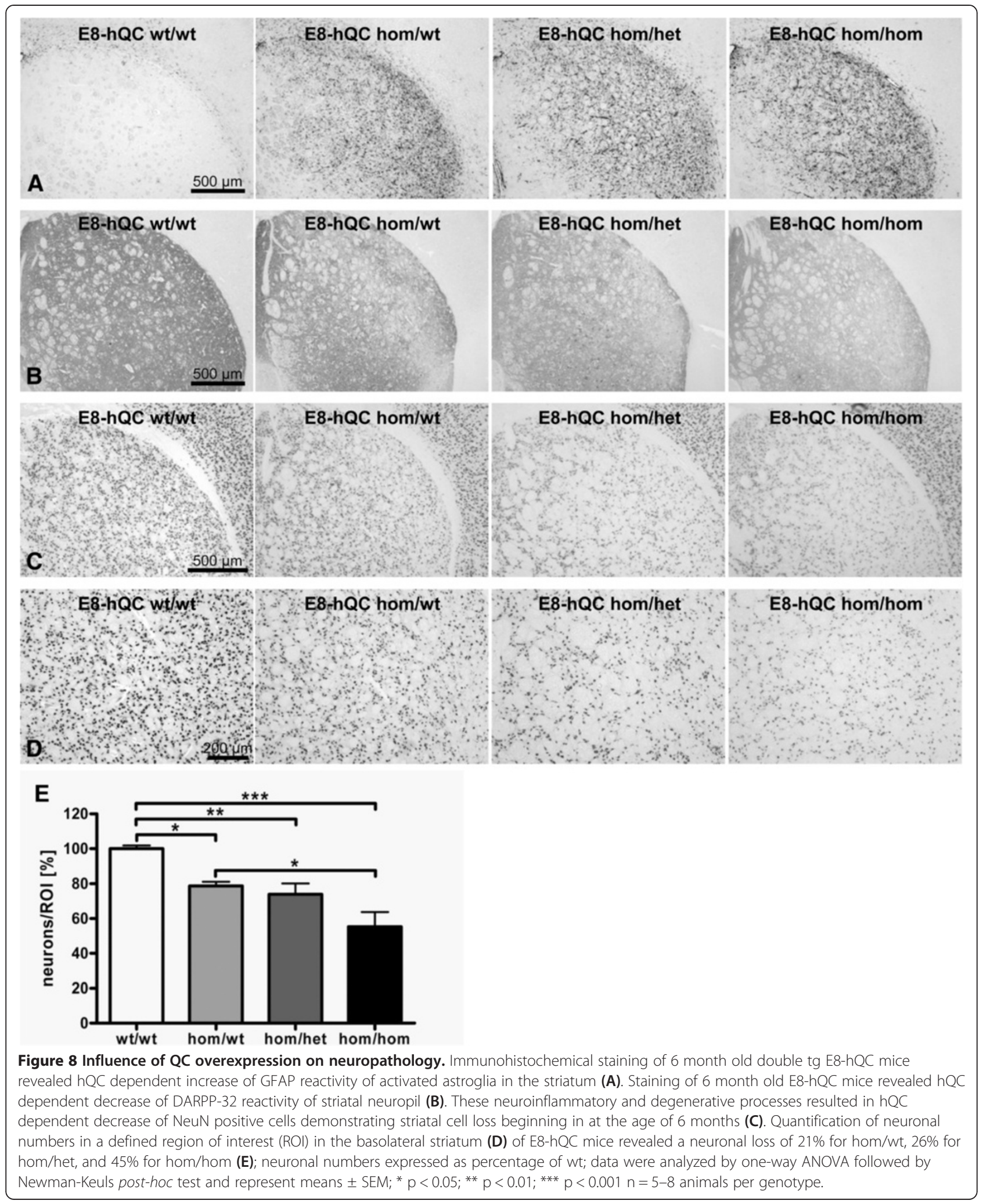

the striatum. In both animal models, TBA2.1 and ETNA, neuronal loss is exclusively observed in vicinity of $\mathrm{pE} 3-\mathrm{A} \beta$, arguing for $\mathrm{pE} 3-\mathrm{A} \beta$ as the neurotoxic $A \beta$ species.
Compared to other unmodified $\mathrm{A} \beta$, pE3-A $\beta$ had been shown to accelerate accumulation of several $A \beta$ species, serving as seed of $A \beta$ aggregation [15-17]. Although, the 
presence of other $A \beta$ species might contribute for the phenotype of ETNA animals, the properties of pE3-A $\beta$ and the spatio-temporal correlation with neuropathology argue for $\mathrm{pE} 3-\mathrm{A} \beta$ as crucial factor. In summary, the presence of $\mathrm{pE} 3-\mathrm{A} \beta$ seems to trigger the coaggregation and to influence the neurotoxic properties of other $A \beta$ species.

Despite for the generation of TBA mice the same Thy1.2 promoter was used as for ETNA mice, in all models a different brain region showed the most expression of the tg construct. In TBA2 the most tg expression was found in the cerebellum [18], TBA2.1 mainly expressed $A \beta$ in the hippocampus [17], and ETNA mice showed most expression in the striatum. The different insertion sites of the tg construct into the genome might have led to the regional variation of expression intensity, but the exact mechanism remains unclear.

Also, the kinetics of pE3-42 deposition and neuropathology implies a crucial role of the modified peptide for neuronal loss. Already at the age of 1 month (first time point of analysis), hom E8 show expression of the truncated $A \beta(3-42)$ construct in the lateral striatum and severe $A \beta$ protein levels of brain homogenates were detected by ELISA. With 3 months of age $A \beta$ expression of hom E8 animals is increasing, reaching a plateau at 6 months. At this age, immunohistochemical stainings then revealed exponential $\mathrm{pE} 3-\mathrm{A} \beta$ formation being associated with immunoreactivity specific for activated astroglia, increased caspase 3 activity, decrease of DARPP-32 expression, and blunted NeuN immunoreactivity, which altogether describe neuroinflammatory and apoptotic neurodegenerative processes.

In temporal correlation of prominent $\mathrm{pE} 3-\mathrm{A} \beta$ formation first behavioral alterations were detected in single tg ETNA animals and at the age of 6 months $90 \%$ of hom E8 animals showed decreased reactivity on a given acoustic signal. These animals showed obvious neuronal loss in the lateral striatum at the age of 9 months and hyperactivity was detected at the age of 10 months.

In het/het E85 animals the same chronology of neuropathology and behavioral phenotype was observed with a delay of 2-4 months.

Moreover, overexpression of hQC has been described to enhance $\mathrm{pE} 3-\mathrm{A} \beta$ dependent pathology and behavior in 5XFAD-hQC mice [34]. To further analyze the role of QC on pE3-A $\beta$ formation and neuropathology, E8 and E85 animals were intercrossed with human QC overexpressing mice to generate double tg ETNA-hQC mice.

These mice showed elevated pE3-A $\beta$ levels and increased neuropathology compared to single tg ETNA mice providing evidence for QC-dependent formation of neurotoxic $\mathrm{pE} 3-\mathrm{A} \beta$ in vivo. Overexpression of hQC had no influence on total $A \beta$ levels detected by ELISA in both ETNA-hQC lines (E8-hQC and E85-hQC), but increased $\mathrm{pE} 3-\mathrm{A} \beta$ levels and numbers of $\mathrm{pE} 3-\mathrm{A} \beta$ positive cells in the lateral striatum. Double tg E8-hQC animals showed hQC gene dose-dependent increase of GFAP and decrease of DARPP-32 reactivity in the striatum at 6 months of age. Neuronal numbers were quantified in the basolateral striatum of these animals and revealed a significantly increased neuronal loss of $45 \%$ for hom/hom E8-hQC animals compared to 21\% for hom/wt E8-hQC animals with hQC wt expression. Enhanced pE3-A $\beta$ formation and pathology in hQC overexpressing animals provide direct evidence for a QC-driven process, limited by the available amount of QC.

The striatal pathology of ETNA contrasts with other mouse models such as TBA2.1 or hAPP tg mice [35-37]. In most of these models, hippocampal (and cortical) degeneration has been observed. ETNA mice display only weak expression of the construct in the pyramidal cell layer of the hippocampus (Additional file 1: Figure S1C), from the age of 3 months and no $\mathrm{pE} 3-\mathrm{A} \beta$ formation is observed up to the age of 9 months in E5, E8, and E85 animals (data not shown).

In accordance with the striatal neuronal loss, sensorimotor gating impairments, similar to striatal alterations in HD, have been observed in ETNA mice [38]. Likewise, in mice with a genetic deletion of DARPP-32 or with point mutations in phosphorylation sites of DARPP-32, the effects of stimulating drugs on sensorimotor gating were strongly attenuated [39].

Impairment of acoustic sensorimotor gating is associated with striatal neurodegeneration occurring at the sites of $\mathrm{pE} 3-\mathrm{A} \beta$ expression and diminished DARPP-32 immunoreactivity.

Similarly, the home cage hyperactivity displayed by single tg ETNA mice is likely to be a consequence of the underlying striatal pathology, possibly caused by a loss of GABAergic inhibitory neurotransmission resulting in a disinhibition of motor function.

While hyperkinetic movement disorders represent an important subgroup of neurodegenerative disorders, not all of those affect the striatum [40]. Among them, HD shows the highest incidence and has been associated with disturbed dopaminergic as well as downstream DARPP-32 neurotransmission [41,42]. A loss of inhibitory GABAergic MSNs represents a key feature of the disease and is causal for hyperactivity [43]. In addition to their relevance for $\mathrm{pE} 3-\mathrm{A} \beta$ toxicity in $\mathrm{AD}$, ETNA lines might model selected aspects of HD.

\section{Conclusions}

Taken together, ETNA is a new mouse model for $A \beta$ toxicity and neuronal loss, associated by a region specific behavioral phenotype.

The immunohistological characterization, analysis of protein levels, and behavioral findings of all ETNA lines 
strongly support a crucial role of QC-catalyzed pE3-A $\beta$ for induction and progression of striatal neuronal loss. Therefore, the model might be also of interest for investigation of the role of striatal factors such as DARPP-32 or others in neuronal degeneration in HD as well as for testing of neuroprotective strategies targeting striatal degeneration.

\section{Appendix 1 \\ Construct Expression in ETNA animals}

To identify the expression pattern of the tg product $\mathrm{A} \beta(3-42)$, coronal brain sections of E5, E8 and E85 from different brain regions and at different ages were stained with the anti- $\mathrm{A} \beta$ antibody $6 \mathrm{E} 10$. In all lines, highest immunoreactivity was found in the striatum (Additional file 1: Figure S1A). Obvious immunoreactivity was also detected in amygdala (Additional file 1: Figure S1B) and single $6 \mathrm{E} 10$ positive cells were found in cortex and brainstem (Additional file 1: Figure S1D, E) up to the age of 9 months. $6 \mathrm{E} 10$ reactivity in the pyramidal cell layer of the hippocampus of ETNA was observed (Additional file 1: Figure S1C), but up to the age of 9 months (latest time point of analysis) no $\mathrm{pE} 3-\mathrm{A} \beta$ formation was found (data not shown).

\section{Protocol of $\mathrm{pE} 3-\mathrm{A} \beta$ cell and neuronal quantification}

For quantification $8 \mu \mathrm{m}$ coronal sections, of the right hemisphere, corresponding to stereotaxic levels bregma $0.14 \mathrm{~mm}$ to $0.38 \mathrm{~mm}$ (as defined in Paxinos and Franklin, 2008) were used for analysis $(\mathrm{n}=3-12$ sections per animal).

Images of $\mathrm{pE} 3-\mathrm{A} \beta$ stained slides were taken at $4 \times$ magnification $(2.9 \mathrm{~mm} \times 2.2 \mathrm{~mm})$, including all stained striatal cells (Additional file 2: Figure S2A). To quantify neuronal numbers, parallel sections were stained with NeuN (Additional file 2: Figure S2C). To quantify only striatal cells a ROI was defined (Additional file 2: Figure S2D). All images were taken with constant exposure time and color balance with the Picture Frame Application 2.3 (Optronics) using a Nikon Eclipse 80i microscope (Nikon Instruments) with a MicroFIRE2.3A camera (Optronics), were saved as Tagged Image Files (TIF-24-bit) at a resolution of $213 \mathrm{dpi}(1600 \mathrm{px} \times 1200$ px) and analyzed with CP.

\section{Region of interest}

To avoid neuronal density variances in the striatum due to high amount of neuropil in the medial striatum a rectangular ROI was defined in the basolateral striatum by using $10 \times$ optical magnification $(1.6 \mathrm{~mm} \times 0.87 \mathrm{~mm})$ with maximal lateral position with maximal possible distance of the lateral ventricle touching the external capsule (ec) and only including cells of the striatum (Additional file 2: Figure S2).

\section{Pipeline quantification of $\mathrm{pE} 3-\mathrm{A} \beta$ positive cells}

Load images: Images at $4 \times$ optical magnification $(2.9 \mathrm{~mm} \times 2.2 \mathrm{~mm})$ including all $\mathrm{pE} 3-\mathrm{A} \beta$ stained cells of the striatum were loaded.

Image math: Images were inverted. $\mathrm{CP}$ usually detects bright immunofluorescence signals with a dark background. By inverting immunohistochemical images, $\mathrm{CP}$ is able to distinguish dark objects from unstained background.

Color to grey: Images were converted from RGB to greyscale. $\mathrm{CP}$ uses grayscale pictures.

Identify primary objects: The minimum diameter was set to 1 pixel, and the maximum diameter was set to 10 pixels. Objects outside the diameter range were excluded. Cells were identified based on their immunohistochemical signal by the 'robust background global' algorithm. The threshold correction factor was set to 1.4. Threshold bounds were set from 0.0-1.0. Clumped objects were distinguished by staining intensity. Identified objects were called ' $\mathrm{pE} 3-\mathrm{A} \beta$ positive cells'.

Export to spreadsheet: After finishing the analysis, data was exported to ".xls for further statistical processing.

\section{Pipeline quantification of neurons in the basal lateral striatum}

An example of the used pipeline is shown in Additional file 3: Figure S3A.

Load images: Images at $10 \times$ optical magnification $(1.6 \mathrm{~mm} \times 0.87 \mathrm{~mm})$ of the ROI, including only NeuN stained cells of the striatum were loaded.

Image math: Images were inverted.

Color to grey: Images were converted from RGB to greyscale.

Identify primary objects: The minimum diameter was set to 8 pixels, and the maximum diameter was set to 50 pixels. Objects outside the diameter range were excluded. Cells were identified based on their immunohistochemical signal by the 'robust background global' algorithm. The threshold correction factor was set to 1.1. Threshold bounds were set from 0.3-1.0. Clumped objects were distinguished by staining intensity. Identified objects were called 'neurons' (Additional file 3: Figure S3B).

Export to spreadsheet: After finishing the analysis, data was exported to *xls for further statistical processing.

\section{Additional files}

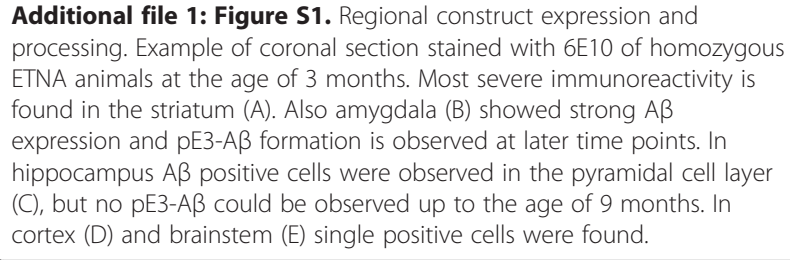


Additional file 2: Figure S2. Image examples and region of interest. Example of ETNA striatal coronal section stained with $\mathrm{pE} 3-\mathrm{A} \beta$ specific antibody, used to quantify pE3-A $\beta$ positive cells by CP software (A). Images were taken at $4 \times$ magnification and automatically inverted and transformed into grayscale (B). CP software detects numbers of stained cells and staining artifacts were excluded by low staining intensity and size above 10 pixels. To quantify neuronal numbers of ETNA striatal coronal sections were stained with NeuN-specific antibody. A ROI was defined as image at $10 \times$ magnification $(1.6 \mathrm{~mm} \times 0.87 \mathrm{~mm})$ in the basal, lateral striatum with maximal possible distance from lateral ventricle (LV), touching the external capsule (ec) and only including cells of the striatum (C). Example of ROI used for neuronal quantification (D).

Additional file 3: Figure S3. Pipelines and image analysis. Pipeline (left) and 'identify primary objects' module (right) used to quantify neuronal numbers by $\mathrm{CP}$ software (A). Example of neuronal identification and segmentation of clumped cells (B). After inversion and transformation (right upper image), CP detects cells and segments clumped objects by staining intensity (green, right lower image).

\section{Competing interests}

$A B, S K, A A, W J, C B, R S$, and $S G$ are or were employed by Ingenium Pharmaceuticals $\mathrm{GmbH}$. HC and SS are or were employed by Probiodrug AG. HUD serves as Chief Scientific Officer of Probiodrug AG and as Managing Director of Ingenium Pharmaceuticals GmbH. SvH was consultant to the Probiodrug and Ingenium Group.

\section{Authors' contributions}

$A B$ designed the study, made the experiments, developed the semiautomated image analysis, evaluated the data, and wrote the manuscript. SK and $C B$ characterized the behavioral phenotype and evaluated the data. WJ evaluated the immunohistological methods. AA evaluated the immunohistological methods and wrote the manuscript. FC made the PP experiments. $\mathrm{HC}$ designed the genetic construct. RS designed the genetic construct and made the genotyping experiments. SG and SS designed the study. HUD and SvH critically revised the manuscript. All authors read and approved the final manuscript.

\section{Acknowledgements}

The authors are grateful to Sylvia Garke-Mayerthaler, Andrea Koppius, Mira Kellner, Alexandra Graupner, Marlene Kilian, Daniela Steinmetz, Eike Scheel, Katrin Schulz, and Birgit Koch for their valuable technical assistance. The authors gratefully acknowledge Verena Becker and Nick Healy for proofreading the manuscript.

\section{Author details}

${ }^{1}$ Department of Experimental Therapy, Friedrich-Alexander-University Erlangen-Nürnberg, Palmsanlage 5, 91054 Erlangen, Germany. ${ }^{2}$ Ingenium Pharmaceuticals GmbH, 82152 Martinsried, Germany. ${ }^{3}$ Probiodrug AG, Biocenter, Weinbergweg 22, 06120 Halle (Saale), Germany.

\section{Received: 21 October 2012 Accepted: 18 September 2013}

\section{Published: 1 October 2013}

\section{References}

1. Schilling S, Manhart S, Hoffmann T, Ludwig HH, Wasternack C, Demuth HU: Substrate specificity of glutaminyl cyclases from plants and animals. Biol Chem 2003, 384(12):1583-92.

2. Schilling S, Hoffmann T, Manhart S, Hoffmann M, Demuth HU: Glutaminyl cyclases unfold glutamyl cyclase activity under mild acid conditions. FEBS Lett 2004, 563(1-3):191-6.

3. Seifert F, Schulz K, Koch B, Manhart S, Demuth HU, Schilling S: Glutaminyl cyclases display significant catalytic proficiency for glutamyl substrates. Biochemistry 2009, 48(50):11831-3.

4. Saido TC: Alzheimer's disease as proteolytic disorders: anabolism and catabolism of beta-amyloid. Neurobiol Aging 1998, 19(1 Suppl):S69-75.

5. Tekirian TL, Yang AY, Glabe C, Geddes JW: Toxicity of pyroglutaminated amyloid beta-peptides $3(\mathrm{pE})-40$ and -42 is similar to that of $A$ beta1-40 and -42. J Neurochem 1999, 73(4):1584-9.
6. Saido TC: Involvement of polyglutamine endolysis followed by pyroglutamate formation in the pathogenesis of triplet repeat/ polyglutamine-expansion diseases. Med Hypotheses 2000, 54(3):427-9.

7. Vidal R, Frangione B, Rostagno A, Mead S, Révész T, Plant G, Ghiso J: A stopcodon mutation in the BRI gene associated with familial British dementia. Nature 1999, 399(6738):776-81.

8. Ghiso JA, Holton J, Miravalle L, Calero M, Lashley T, Vidal R, Houlden H, Wood N, Neubert TA, Rostagno A, Plant G, Revesz T, Frangione B: Systemic amyloid deposits in familial British dementia. J Biol Chem 2001, 276(47):43909-14.

9. Schlenzig D, Manhart S, Cinar Y, Kleinschmidt M, Hause G, Willbold D, Funke SA, Schilling S, Demuth HU: Pyroglutamate formation influences solubility and amyloidogenicity of amyloid peptides. Biochemistry 2009, 48(29):7072-8.

10. Schlenzig D, Rönicke R, Cynis H, Ludwig HH, Scheel E, Reymann K, Saido T, Hause G, Schilling $S$, Demuth HU: N-Terminal pyroglutamate formation of $A \beta 38$ and $A \beta 40$ enforces oligomer formation and potency to disrupt Hippocampal long-term Potentiation. J Neurochem 2012, 121(5):774-84.

11. Saido TC, Iwatsubo T, Mann DM, Shimada H, Ihara Y, Kawashima S: Dominant and differential deposition of distinct beta-amyloid peptide species, A beta N3(pE), in senile plaques. Neuron 1995, 14(2):457-66.

12. Selkoe DJ: Alzheimer's disease: genes, proteins, and therapy. Physiol Rev 2001, 81(2):741-66.

13. Zhang $H, M a Q$, Zhang YW, Xu H: Proteolytic processing of Alzheimer's $\beta$ amyloid precursor protein. J Neurochem 2012, 120(Suppl 1):9-21.

14. Cynis H, Rahfeld JU, Stephan A, Kehlen A, Koch B, Wermann M, Demuth HU, Schilling S: Isolation of an isoenzyme of human glutaminyl cyclase: retention in the Golgi complex suggests involvement in the protein maturation machinery. J Mol Biol 2008, 379(5):966-80.

15. He W, Barrow CJ: The A beta 3-pyroglutamyl and 11-pyroglutamyl peptides found in senile plaque have greater beta-sheet forming and aggregation propensities in vitro than full-length $\mathrm{A}$ beta. Biochemistry 1999, 38(33):10871-7.

16. D'Arrigo C, Tabaton M, Perico A: N-terminal truncated pyroglutamyl beta amyloid peptide Abetapy3- 42 shows faster aggregation kinetics than the full-length Abeta1-42. Biopolymers 2009, 91(10):861-73.

17. Alexandru A, Jagla W, Graubner S, Becker A, Bäuscher C, Kohlmann S, Sedlmeier R, Raber KA, Cynis H, Rönicke R, Reymann KG, Petrasch-Parwez E, Hartlage-Rübsamen M, Waniek A, Rossner S, Schilling S, Osmand AP, Demuth $\mathrm{HU}$, von Hörsten S: Selective hippocampal neurodegeneration in transgenic mice expressing small amounts of truncated $A \beta$ is induced by pyroglutamate-A $\beta$ formation. J Neurosci 2011, 31(36):12790-801.

18. Wirths $\mathrm{O}$, Breyhan $\mathrm{H}$, Cynis $\mathrm{H}$, Schilling $\mathrm{S}$, Demuth HU, Bayer TA: Intraneuronal pyroglutamate-Abeta 3-42 triggers neurodegeneration and lethal neurological deficits in a transgenic mouse model. Acta Neuropathol 2009, 118(4):487-96.

19. Wittnam JL, Portelius E, Zetterberg H, Gustavsson MK, Schilling S, Koch B, Demuth HU, Blennow K, Wirths O, Bayer TA: Pyroglutamate amyloid $\beta$ (AB) aggravates behavioral deficits in transgenic amyloid mouse model for Alzheimer disease. J Biol Chem 2012, 287(11):8154-62.

20. Lüthi A, Van der Putten H, Botteri FM, Mansuy IM, Meins M, Frey U, Sansig G, Portet C, Schmutz M, Schröder M, Nitsch C, Laurent JP, Monard D: Endogenous serine protease inhibitor modulates epileptic activity and Hippocampal long-term Potentiation. J Neurosci 1997, 17(12):4688-99.

21. Friedman TC, Loh YP, Cawley NX, Birch NP, Huang SS, Jackson IM, Nillni EA: Processing of prothyrotropin-releasing hormone (Pro-TRH) by bovine intermediate lobe secretory vesicle membrane PC1 and PC2 enzymes. Endocrinology 1995, 136(10):4462-72.

22. Cynis H, Schilling S, Bodnár M, Hoffmann T, Heiser U, Saido TC, Demuth HU: Inhibition of glutaminyl cyclase alters pyroglutamate formation in mammalian cells. Biochim Biophys Acta 2006, 1764(10):1618-25.

23. Siebert PD, Chenchik A, Kellogg DE, Lukyanov KA, Lukyanov SA: An improved PCR method for walking in uncloned genomic DNA. Nucleic Acids Res 1995, 23:1087-1088.

24. Rogers DC, Fisher EM, Brown SD, Peters J, Hunter AJ, Martin JE: Behavioral and functional analysis of mouse phenotype: SHIRPA, a proposed protocol for comprehensive phenotype assessment. Mamm Genome 1997, 8(10):711-3.

25. Karl T, Pabst R, von Hörsten S: Behavioral phenotyping of mice in pharmacological and toxicological research. Exp Toxicol Pathol 2003, 55(1):69-83. 
26. Paxinos G, Franklin KB: The mouse brain in stereotaxic coordinates. San Diego: Elsevier Academic; 2008.

27. Carpenter AE, Jones TR, Lamprecht MR, Clarke C, Kang IH, Friman O, Guertin DA, Chang JH, Lindquist RA, Moffat J, Golland P, Sabatini DM: CellProfiler: image analysis software for identifying and quantifying cell phenotypes. Genome Biol 2006, 7(10):R100.

28. Nillni EA, Sevarino KA: The biology of pro-thyrotropin-releasing hormonederived peptides. Endocr Rev 1999, 20(5):599-648.

29. Spongr VP, Flood DG, Frisina RD, Salvi RJ: Quantitative measures of hair cell loss in CBA and C57BL/6 mice throughout their life spans. J Acoust Soc Am 1997, 101(6):3546-53.

30. Keithley EM, Canto C, Zheng QY, Fischel-Ghodsian N, Johnson KR: Age-related hearing loss and the ahl locus in mice. Hear Res 2004, 188(1-2):21-8.

31. Kummer MP, Hermes M, Delekarte A, Hammerschmidt T, Kumar S, Terwel D, Walter J, Pape HC, König S, Roeber S, Jessen F, Klockgether T, Korte M, Heneka MT: Nitration of tyrosine 10 critically enhances amyloid $\beta$ aggregation and plaque formation. Neuron 2011, 71(5):833-44

32. Nussbaum JM, Schilling S, Cynis H, Silva A, Swanson E, Wangsanut T, Tayler K, Wiltgen B, Hatami A, Rönicke R, Reymann K, Hutter-Paier B, Alexandru A, Jagla W, Graubner S, Glabe CG, Demuth HU, Bloom GS: Prion-like behaviour and tau-dependent cytotoxicity of pyroglutamylated amyloidB. Nature 2012, 485(7400):651-5.

33. Svenningsson P, Nishi A, Fisone G, Girault JA, Nairn AC, Greengard P: DARPP-32: an integrator of neurotransmission. Annu Rev Pharmacol Toxicol 2004, 44:269-96.

34. Jawhar S, Trawicka A, Jenneckens C, Bayer TA, Wirths O: Motor deficits, neuron loss, and reduced anxiety coinciding with axonal degeneration and intraneuronal $A \beta$ aggregation in the SXFAD mouse model of Alzheimer's disease. Neurobiol Aging 2010, 33(1):e29-40. 196.

35. Rockenstein EM, McConlogue L, Tan H, Power M, Masliah E, Mucke L: Levels and alternative splicing of amyloid beta protein precursor (APP) transcripts in brains of APP transgenic mice and humans with Alzheimer's disease. J Biol Chem 1995, 270(47):28257-67.

36. Mucke L, Masliah E, Yu GQ, Mallory M, Rockenstein EM, Tatsuno G, Hu K Kholodenko D, Johnson-Wood K, McConlogue L: High-level neuronal expression of abeta 1-42 in wild-type human amyloid protein precursor transgenic mice: synaptotoxicity without plaque formation. J Neurosci 2000, 20(11):4050-8.

37. McGowan E, Eriksen J, Hutton M: A decade of modeling Alzheimer's disease in transgenic mice. Trends Genet 2006, 22(5):281-9.

38. Swerdlow NR, Paulsen J, Braff DL, Butters N, Geyer MA, Swenson MR: Impaired prepulse inhibition of acoustic and tactile startle response in patients with Huntington's disease. J Neurol Neurosurg Psychiatry 1995, 58(2):192-200

39. Svenningsson P, Tzavara ET, Carruthers R, Rachleff I, Wattler S, Nehls M, McKinzie DL, Fienberg AA, Nomikos GG, Greengard P: Diverse psychotomimetics act through a common signaling pathway. Science 2003, 302(5649):1412-5.

40. Jellinger KA: Neurodegenerative Erkrankungen (ZNS) - Eine aktuelle Übersicht. J Neurol Neurochir Psychiatr 2005, 6(1):9-18.

41. Miller BR, Walker AG, Fowler SC, von Hörsten S, Riess O, Johnson MA, Rebec GV: Dysregulation of coordinated neuronal firing patterns in striatum of freely behaving transgenic rats that model Huntington's disease. Neurobiol Dis 2010, 37(1):106-13.

42. Zuccato C, Valenza M, Cattaneo E: Molecular mechanisms and potential therapeutical targets in Huntington's disease. Physiol Rev 2010, 90(3):905-81.

43. Bateup HS, Santini E, Shen W, Birnbaum S, Valjent E, Surmeier DJ, Fisone G, Nestler EJ, Greengard P: Distinct subclasses of medium spiny neurons differentially regulate striatal motor behaviors. Proc Natl Acad Sci USA 2010, 107(33):14845-50.

doi:10.1186/1471-2202-14-108

Cite this article as: Becker et al:: Glutaminyl cyclase-mediated toxicity of pyroglutamate-beta amyloid induces striatal neurodegeneration. BMC Neuroscience 2013 14:108.

\section{Submit your next manuscript to BioMed Central and take full advantage of:}

- Convenient online submission

- Thorough peer review

- No space constraints or color figure charges

- Immediate publication on acceptance

- Inclusion in PubMed, CAS, Scopus and Google Scholar

- Research which is freely available for redistribution

Submit your manuscript at www.biomedcentral.com/submit
C Biomed Central 